\title{
COMPARATIVE STUDY OF A HYPERBOLIC CIRCULAR DIAGRID STEEL STRUCTURE REHABILITATED AT CORE WITH SHEAR WALL AND STEEL BRACED FRAMES
}

\author{
Nandeesh K C $\mathbf{C}^{1}$, Geetha $\mathrm{K}^{2}$ \\ ${ }^{1}$ MTech Student, Department of Civil Engineering, EWIT, Bangalore, Karnataka, India \\ ${ }^{2}$ Assistant Professor, Department of Civil Engineering, EWIT, Bangalore, Karnataka, India
}

\begin{abstract}
In contemporary decades, the requirements of the people groups are more for business reason. For that the creating of constructional procedure was enhanced by developing the tall structures. So late tall structures would have more convoluted basic conduct than some time recently. In the event that the stature of the building is goes on expansion while the conduct of the tall building get to be basic as far as straight and non-direct cases. From the thought of basic conduct we need to oppose that basic viewpoints by giving parallel burden opposing frameworks. For the perspective of auxiliary effectiveness and compositional noteworthy give half and half structures by giving the center core at the focal point of the tall structures and diagrid at the fringe of the structures even its disposing of the sections at the border of the tall building. The diagrid framework is just the helpful strategy to give at fringe of a hyperbolic circular about structure since that all floor range are straightly fluctuating to each other, in this manner the vertical sections are not great to give at border of the all floor regions. The motivation behind this paper is to examine the seismic reaction and wind analysis of a hyperbolic circular diagrid structure rehabilitated with shear wall and steel braced frames. Since the hyperbolic circular tall structures are additionally one of the convoluted structure. So in this project we concentrate on the straight static conduct of that specific convoluted structure utilizing programming. In this work basically comprise of two models with shifting floor zone and center divider framework. The external fringe comprise of diagrid funnel segment for both models. These models are examined for two distinctive seismic zones (zone2 and zone3). All the models and its components are investigated utilizing ETABs programming according to Indian codes. This work shows the outcomes parameter regarding story drift, story displacement, time period, story shear and modes.
\end{abstract}

Keywords: Response spectrum Analysis, diagrid, shear wall, inverted V bracings, storey displacement, storey shear, storey drift, time periods etc...

\section{INTRODUCTION}

The development in cutting edge tall structures has been to a great extent for business and private purposes. The tallness of a building involves a man's or group circumstances and their resulting discernment; accordingly a quantifiable meaning of a tall building can't be all a circular connected. From the auxiliary specialist's perspective, however a tall building might be characterized as one that as a result of its stature is influenced by horizontal strengths because of wind and seismic tremor activities to a degree that they assume a critical part in the basic configuration. The impact of these activities should thusly be considered from the earliest starting point of the outline procedure. Today's tall structures are turning out to be increasingly thin, prompting the likelihood of more influence in correlation with prior elevated structures. Along these lines the import of wind and seismic powers following up on them turns into an essential part of the outlines. Enhancing the basic frameworks of tall structures can control their dynamic reaction. The auxiliary types of tall structures, for example, shear divider and supported tube structures and enhanced the properties of material and the most extreme stature of solid structures has taken off in modern decades. In this way the time reliance of cement and steel has turned into another vital component that ought to be considered in examination to have a more sensible and sparing outline.

The diagrid word is a portmanteau of slanting framework. Diagrid is an outline for developing expansive structures with steel that makes triangular structures with slanting bolster shafts. Diagrid is an arrangement of triangulated bars, straight or bended and even rings that together make up a basic framework for a high rise. The diagrid auxiliary frameworks expands the basic proficiency and prominence of the building. The diagrid frameworks can be tackled numerous ebb and flow of the structure. The firmness of the structure is expanded with utilization of crystalline structures or arch offered by diagrid structure. The diagrid auxiliary framework are given at border of the structure to wipe out the vertical segments and convey the parallel and gravity heaps of the structures and are additionally used to bolster the edge states of the floors.

In tall structures the center structure are essential parts for opposing gravity stress and parallel stress. The center might be 
halfway situated with outrigger reaching out on both sides or sometimes it might be situated on one sides of the working with outriggers stretching out to the building segments on alternate sides. The fortified solid divider which is the major basic burden bearing components and gives unbending nature to oppose diversion created by solid winds. The auxiliary steel propped casings are likewise utilized as a part of the center structures rather than fortified solid divider or shear divider. With the arrangement of steel segment with bracings and bars are situated along the border of the center to withstand the parallel powers existing at the outside components are to be exchanged to the center structure and it will take all the powers which is coming over on it.

Shear walls, made of reinforced bond, are used as a piece of front line structures because of their ampleness in keeping up strength and for the adaptability they offer the architect who is arranging. A shear divider's position in a building is every now and again at first picked by the organizer. The modeler is set up to get ready for the structures limit and appearance and not for its constancy so when a helper designer is excluded in the essential time of setup, it may incite the shear dividers being orchestrated in non-incredible positions. In like manner, while picking invigorated strong dividers as portion dividers, the sketcher can be coincidentally expanding settling parts. Pierced shear dividers are depicted as shear dividers with crevices. These openings can be windows or portals that are major for access or lighting for the building.

The propping framework is one of the sidelong load opposing framework by giving corner to corner moved steel or tubular areas to the structure, to build the horizontal opposing solidness of the recently built or existing structure. The supporting individuals are fundamentally intended for horizontal stress because of wind and quakes, at times to enhance the basic proficiency of a current structure may likewise outline the propping by the specialized name 'retrofit'. Normally the diverse kind of bracings are utilized, for example, $\mathrm{X}, \mathrm{K}, \mathrm{V}$, reversed $\mathrm{V}$ and so forth they have its individual opposing limit of sidelong loads with its own particular plane.

\section{METHODOLOGY}

\subsection{Aim and Scope}

The main mission of this project is to study the behaviour of structural system of a hyperbolic circular diagrid structures with concrete wall and steel braced frames at the Centre core wall of structure subjected to lateral loads due to wind and earthquake by using static method and linear dynamic method. In this study, due to the consideration of the effect of lateral loads the variations in structural systems is to be investigated such as story drifts, story displacement, modes, time period and story shears.

\subsection{Objectives}

The main intent of the project is to study the response behaviour of a hyperbolic circular diagrid tall buildings and having the core wall at the center of the buildings which is made up of one by shear wall and another one by steel braced frames and these acts as a lateral load resisting systems for the building.

The motivation behind the present study as takes after.

$>\quad$ To know the effects of hyperbolic circular diagrid structures under static method and dynamic method.

$>\quad$ To quantify lateral sway of internal structural systems with different features.

$>\quad$ To understand and identify which type of internal structure systems i.e. shear wall and steel braced frames are suitable for hyperbolic circular diagrid tall structures.

$>\quad$ To know which type of internal structural elements are more flexible by considering the time periods.

$>\quad$ To know the better structural element combination with diagrid either shear wall or steel braced frames in hyperbolic circular diagrid tall structures.

\subsection{Methodology}

The technique is worked out to accomplish the specified goals is as per the following.

$>\quad$ the modelling of the selected hyperbolic circular diagrid buildings is done by using Etabs software.

$>\quad$ There are totally four models amongst them two models are utilized to analysis for seismic zone 2 and remaining two models are analysis for seismic zone 3 .

$>\quad$ The lateral loads due to wind and seismic loads, its combinations applied as per the codes IS 875 part 3 and IS 1893:2002.

$>$ Retrieved the modes and time periods of structure from the software.

$>\quad$ All models are analyzed for story shear, modes, time period, story displacements, story drifts, story accelerations of the data is presented.

\section{MODEL DESCRIPTION}

The geometric details of the models are as follows.

* Plan of variable radius.

a) Radius at ground floor : $28.8 \mathrm{~m}$

b) Radius at mid height ( $28^{\text {th }}$ floor) $: 19.3 \mathrm{~m}$

c) Radius at fifty second floor : $27.80 \mathrm{~m}$

d) Radius of core : $11.90 \mathrm{~m}$

* Total height of the building : $200.60 \mathrm{~m}$

* Typical storey height : $3.8 \mathrm{~m}$

* Type of bracing : Inverted V bracings

* Slab thickness : 125mm, 150mm, 180mm

* Shear wall thickness : $300 \mathrm{~mm}$

* Compressive strength of concrete: $25 \mathrm{mpa}$, 40mpa

* Sizes of steel sections

- ISMB : 500mm, 600mm, ISHB : $800 \mathrm{~mm}$

* Sizes of diagrid pipe section : $800 \mathrm{~mm}, 1000 \mathrm{~mm}$

* Sizes of bracing: 500mm X 500mm (Hollow rectangular). 


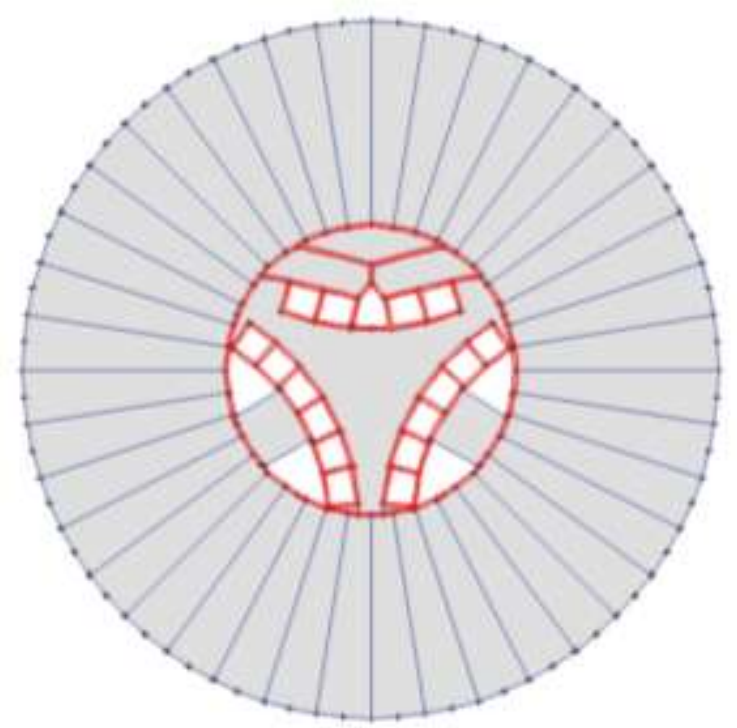

Fig 1: Plan at ground floor of radius $28.8 \mathrm{~m}$.

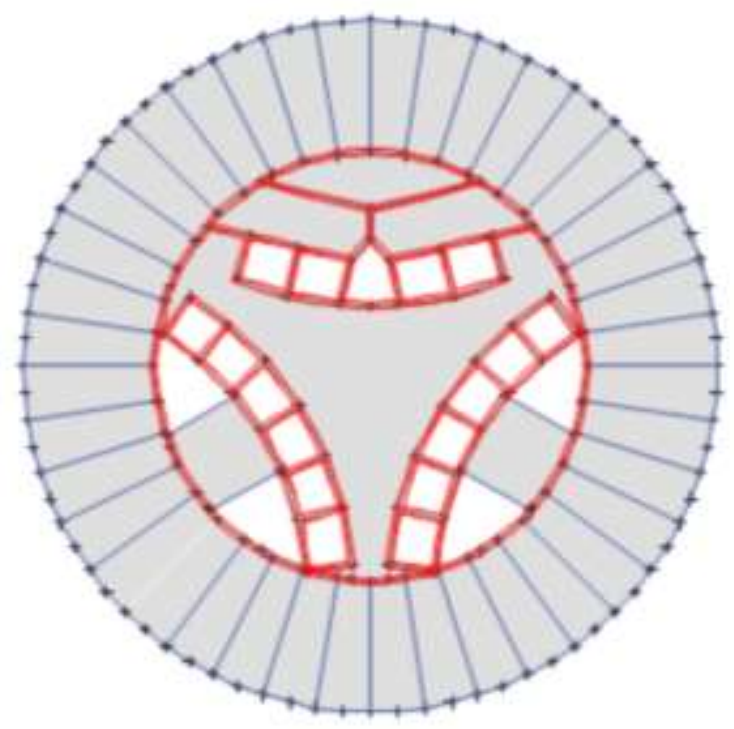

Fig 2: Plan at twenty eighth floor of radius $19.3 \mathrm{~m}$.

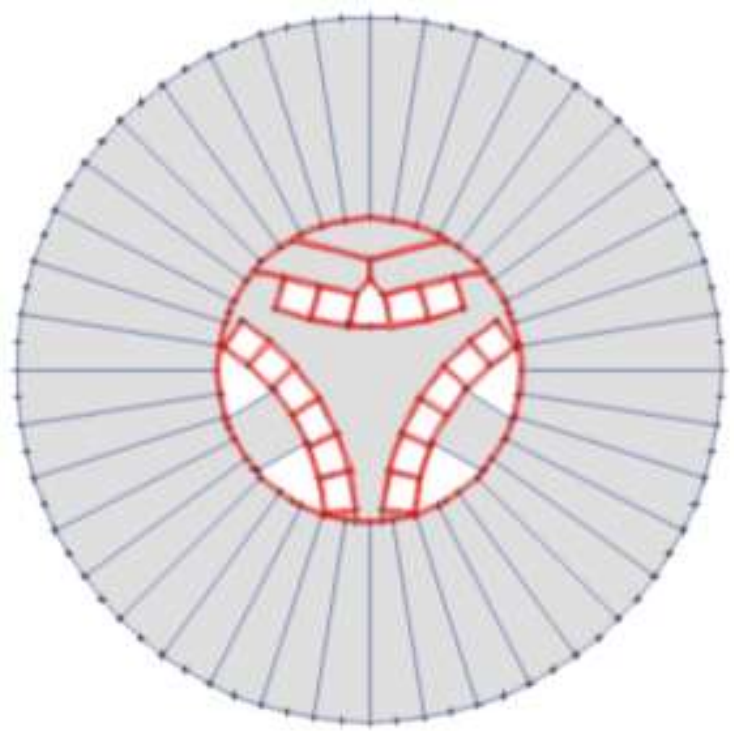

Fig 3: Plan at fifty second floor of radius $27.8 \mathrm{~m}$.
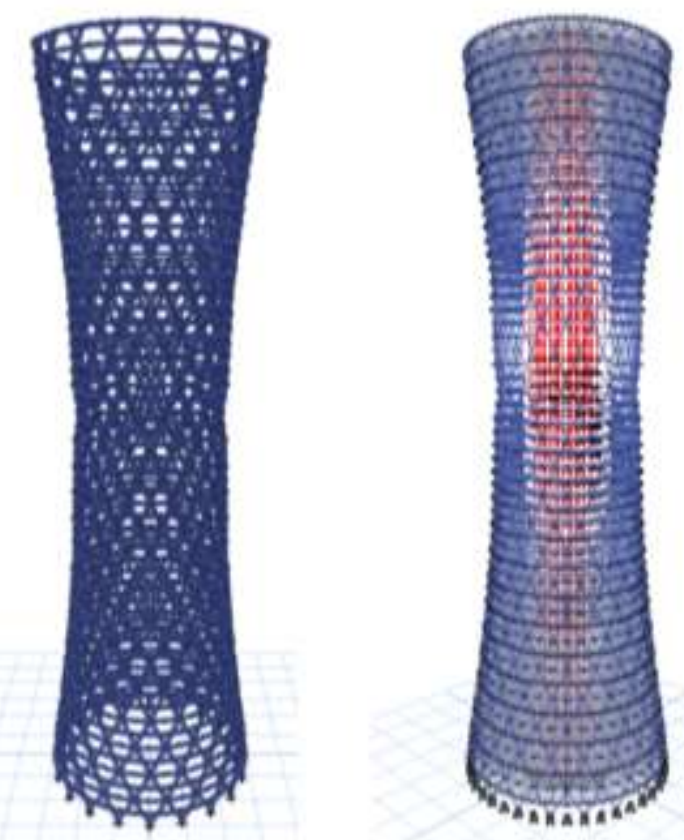

Fig 5: Diagrid elevation of modelling. 
The notations used below are as follows

$>\mathrm{SW}$ Z2 = Hyperbolic circular diagrid structure with shear wall for seismic zone2.

$>\mathrm{SW} \mathrm{Z3}=$ Hyperbolic circular diagrid structure with shear wall for seismic zone3.

$>\mathrm{SBF}$ Z2 = Hyperbolic circular diagrid structure with steel braced frames for seismic zone2.

$>\mathrm{SBF}$ Z3 = Hyperbolic circular diagrid structure with steel braced frames for seismic zone3.

\section{ANALYSIS RESULTS}

The consequences of story uprooting, story float, storey shear and time period for various models are given and contrasted with various models for various sort of center structure and two distinctive seismic zones.

\subsection{Displacements}

All models have the maximum displacement within the permissible limits. Here the models SW Z2 and SW Z3 gives better results to resist the lateral displacement compared to other two models.

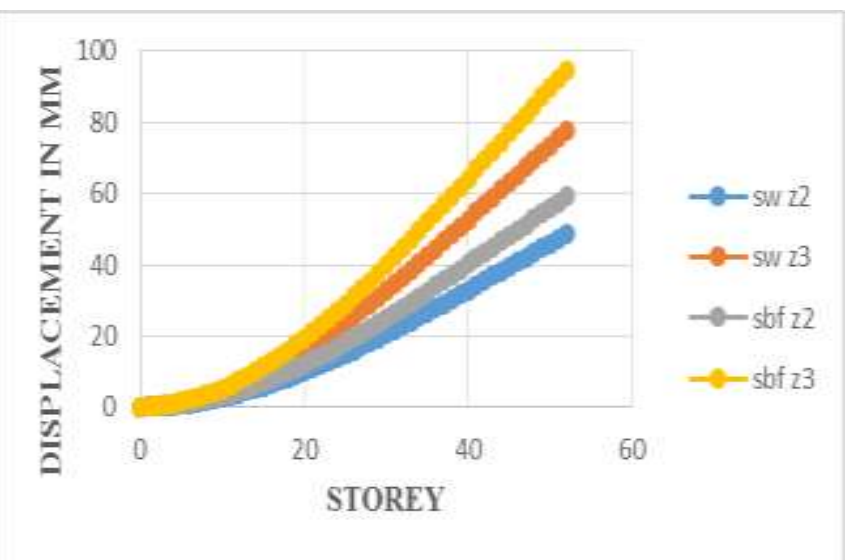

Fig 6: Displacement vs. Storey due to earthquake loads

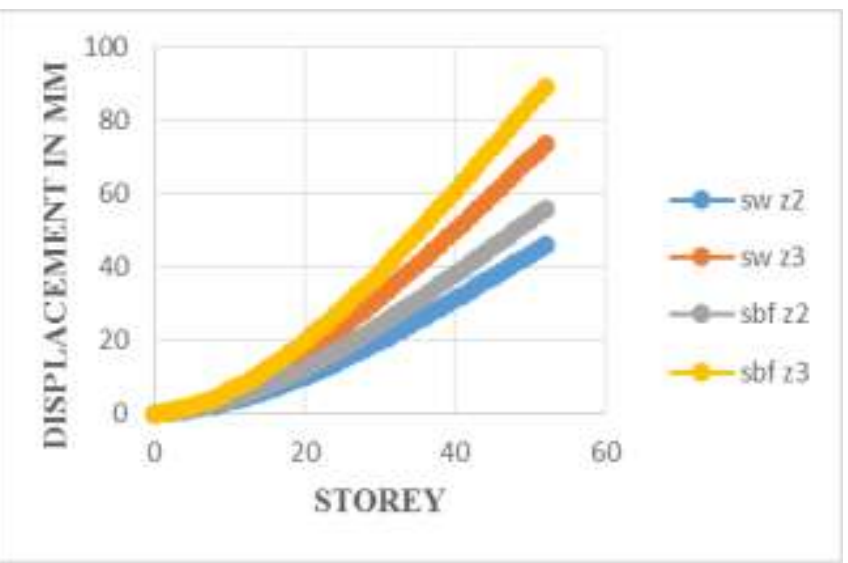

Fig 7: Displacement vs. Storey due to response spectrum loads

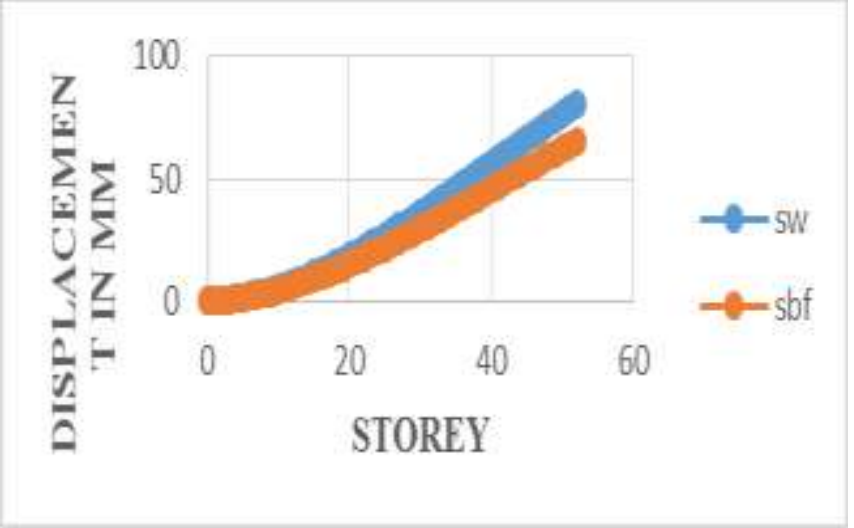

Fig 8: Displacement vs. Storey due to wind loads

\subsection{Storey Drift}

Here all models are have the storey drift value is within the permissible limit. From the results, the models SW Z2 and SW $\mathrm{Z} 3$ are gives good resistance for storey drift compared to other models.

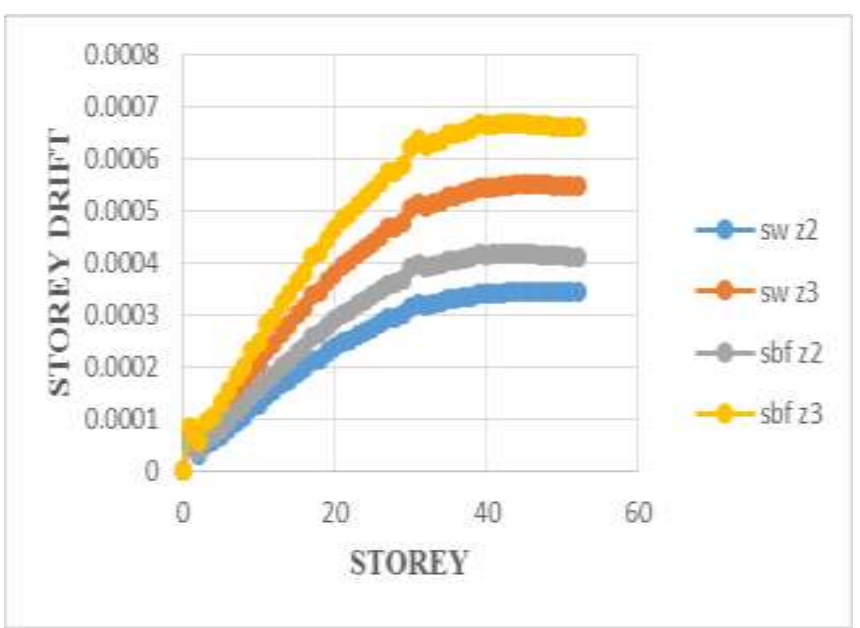

Fig 9: Storey drift vs. Storey due to earthquake loads.

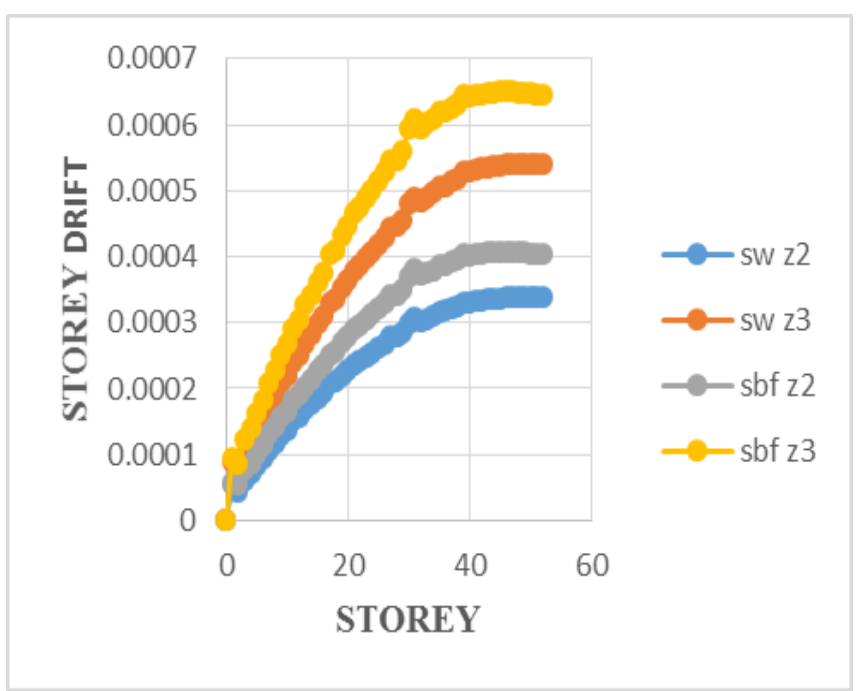

Fig 10: Storey drift vs. Storey due to response spectrum loads 


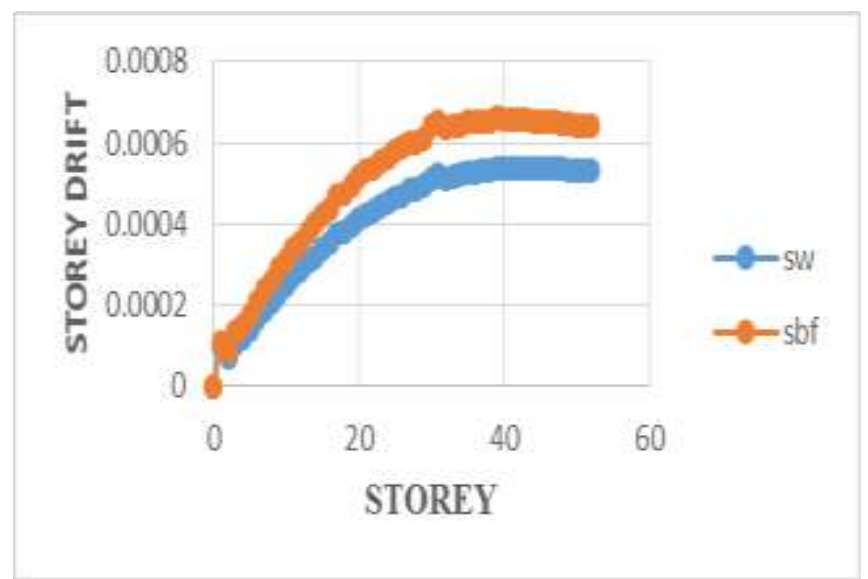

Fig 11: Storey drift vs. Storey due to wind loads

\subsection{Storey Shear}

From the analyzed consequence, it can be observed that the models SW Z2 and SW Z3 are have the more base shear than the models SBF Z2 and SBF Z3. For the earthquake loads the base shear is linearly varying to each other. Similarly for the response spectrum load cases the base shear for all models are unevenly varying to each other. The models SBF Z2 and SBF $\mathrm{Z} 3$ are gives the better results compare to other two models.

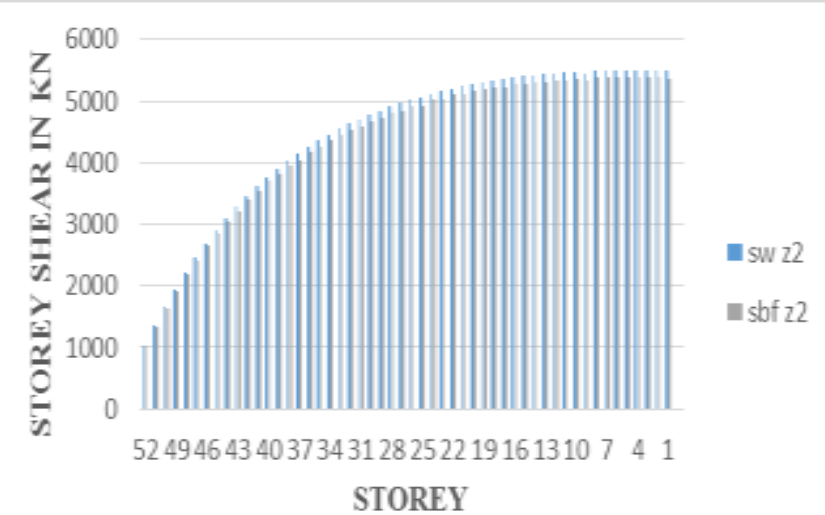

Fig 12: Storey shear vs. storey for sw $z 2$ and sbf $z 2$ due to earthquake loads

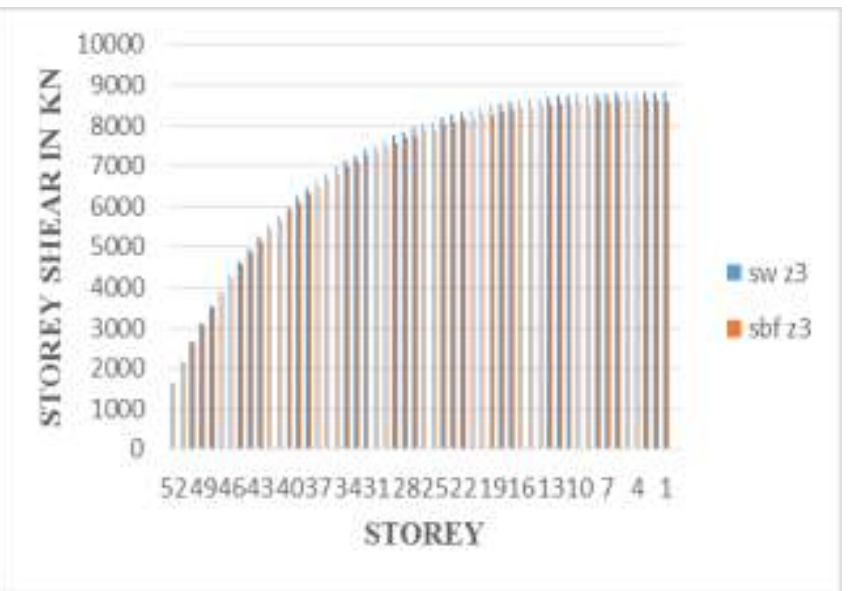

Fig 13: Storey shear vs. storey for sw $z 3$ and sbf $z 3$ due to earthquake loads

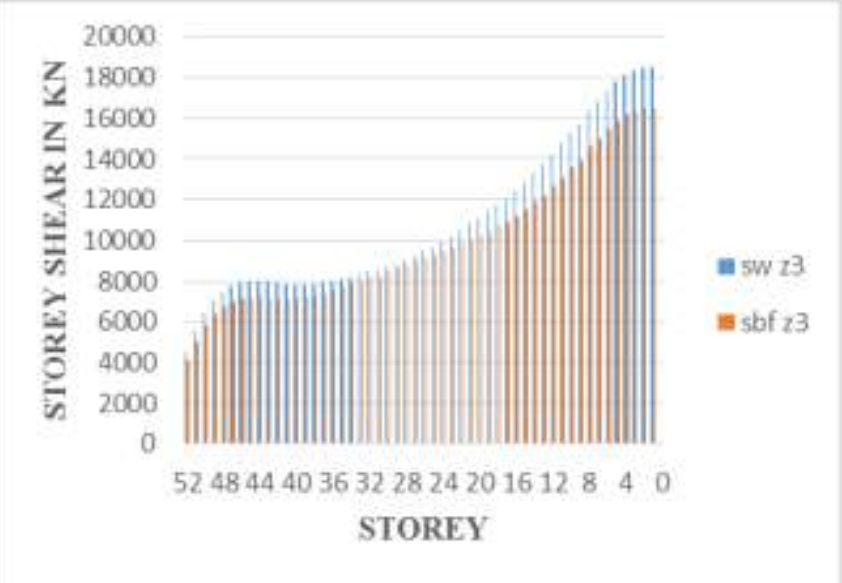

Fig 14: Storey shear vs. storey for sw z3 and sbf z3 due to response spectrum loads

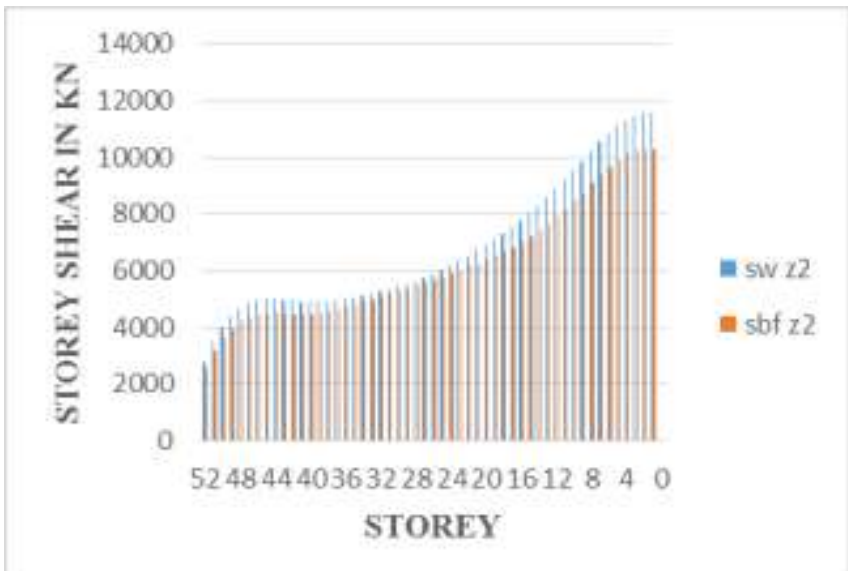

Fig 15: Storey shear vs. storey for sw z2 and sbf z2 due to response spectrum loads.

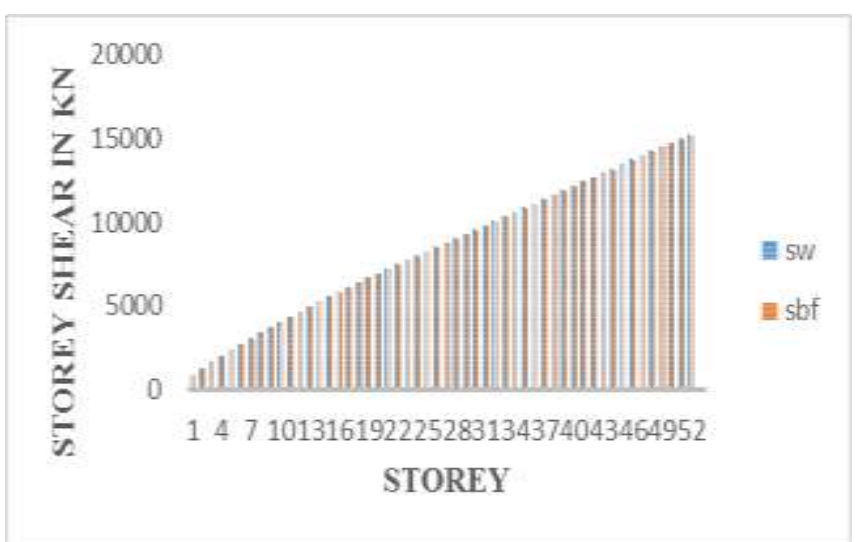

Fig 16: Storey shear vs. Storey due to wind loads

\subsection{Time Period}

The solidness of the structure is considered with the time period values. If the time period value goes on increasing the structure becomes more flexible. If the time period value is less, it means the structure become more stiff. From the analysis outcome, it can be observed that the time period is minimum for the models SW Z2 and SW Z3, so it means that the stiffness of these models is more compared to other two models SBF Z2 and SBF Z3 respectively. 


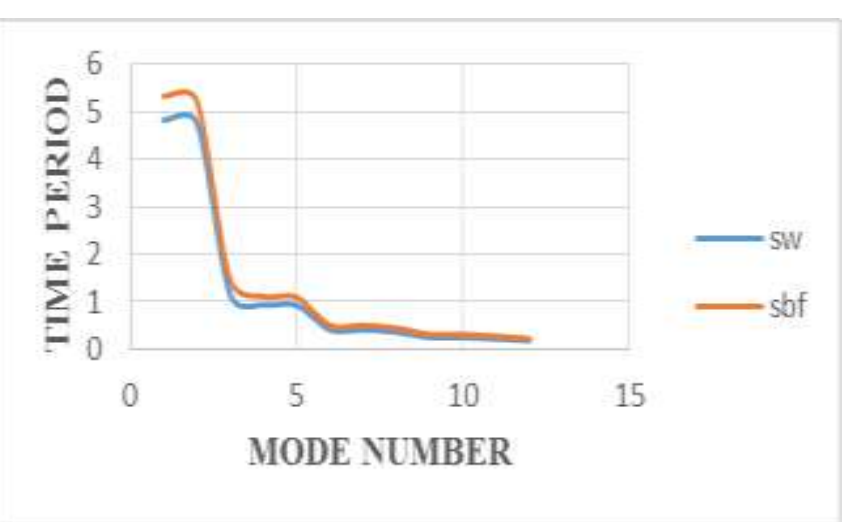

Fig 17: Time period vs. mode number

\section{CONCLUSION}

In this work comparative analysis of 52 storey hyperbolic circular diagrid structural system rehabilitated at central core with shear wall and steel bracing frames are presented. The software is used for modelling and analysis of structure is Etabs 2015. Also comparison is done on the basis of two seismic zones. Analysis results such as storey displacement, storey drift, storey shear and time period are presented here. After the analysis of the structure with different types of core structural system and different seismic zones, taking after are the conclusions construed from the study:

- For all four models considered for the study the storey displacement and storey drift qualities are inside as far as possible.

- The shear wall system shows the better performance under earthquake loading. Itgis having less top storey displacement than steel bracing frames systems.

- The performance of shear wall system against storey drift is better than the steel bracing frame systems in both seismic zones.

- Due to the circular in shape of core, it is better to provide shear wall systems than steel bracing frame systems to gives good performance against lateral displacement and storey drift.

- The shear wall system behaves like monolithic structure for whole core due to its curved in nature. So that it gives better results for all results aspects.

- The steel bracing frame systems gives better performance against storey shear for both seismic zones than shear wall systems.

- The storey shear is linearly varying to each other but the steel bracing frame systems gives the good results than shear wall systems.

- For the higher seismic zones, the steel bracing frame systems gives the good results than shear wall systems in storey shear.

- The shear wall systems has less flexibility than the steel bracing frame systems, so that the stiffness is more in shear wall system than steel bracing frame systems.
So the proposed above modelling, the shear wall systems act as a monolithic structure and gives the effective performance against all aspects in terms of maximum storey displacement, storey drift and time period.

\section{REFERENCES}

[1] MohdAtif, Prof.LaxmikantVairagade, Vikrant Nair, "COMPARATIVE STUDY ON SEISMIC ANALYSIS OF MULTISTOREY BUILDING STIFFENED WITH BRACING AND SHEAR WALL", International Research Journal of Engineering and Technology (IRJET), Volume: 02, Issue: 05, Aug-2015. Pp: 11581170.

[2] Nauman Mohammed, Islam Nazrul, "Behaviour of Multistorey RCC Structure with Different Type of Bracing System", International journal of Innovative Research in Science, Vol: 02, Issue: 12, Dec-2013. Pp: 7465-7478.

[3] FemyMariya Thomas, BinuM.Issac, Jessymol George, "Performance Evaluation of Tall Buildings With Steel Diagrid System", International Conference on science, Technology and Management, Sep-2015. Pp: 2242-2256.

[4] Shachindra Kumar Chandhar, Dr. Abhay Sharma, "Seismic Behaviour of RC Building Frame with Steel Bracing System Using Various Arrangements", International Research Journal of Engineering and Technology, Vol: 02, Issue: 05, Aug-2015. Pp: 479-483.

[5] Rasool. Owais\&Tantray. Manzoor Ahmad, "Comparative Analysis Between Different Commonly Used Lateral Load Resisting Systems in Reinforced Concrete Buildings", Global Journal of Resistance in Engineering, Vol: 16, Issue: 1, 2016.

[6] Lekshmi Mohan, C.K. Prasad VarmaThampan, "Numerical Modelling and Evaluation of Hybrid Diagrid Structures", International Journal of Research in Advent Technology, June-2015. Pp: 149-153.

[7] K. Moon, "Diagrid and Construction of Steel Diagrid Structures", 2009. Pp: 398-405.

[8] IS 456: 2000, "Indian Standard Code of Practice for Plain and Reinforced Concrete", Bureau of Indian Standards, New Delhi, 2000.

[9] IS 1893(Part 1): 2002, “Criteria for Earthquake Resistant Design of Structures" Part 1 General Provision and Buildings. Bureau of Indian Standards, New Delhi, 2002.

[10] IS 800: 2007, Indian Standard Code of Practice for General Construction in Steel, Bureau of Indian Standards, New Delhi.

[11] S.S. Bhavikkatti, K.V. Pramod, "Steel Tables with Plastic Modulus of IS Sections".

[12] IS 875: 1987(Part 2 \& Part 3), Indian Standard Code of Practice for Design Loads (Other than Earthquake) for Buildings and Structures, Bureau of Indian Standards, New Delhi. 


\section{BIOGRAPHIES}

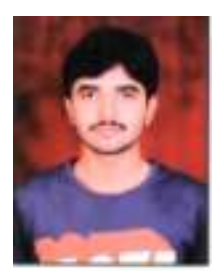

I am Mr. Nandeesh k c. I am pursuing my masters of technology in structural engineering from East west institute of technology, Bangalore. I am doing my dissertation work under the guidance of Mrs. Geetha k. I have pursued my B.E, civil engineering from Government engineering college, Ramanagara.

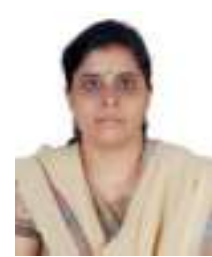

She is Mrs. Geetha k Assistant professor, Department of civil engineering, East west institute of technology, Bangalore. She is also worked in structural design consultant and designed various projects. She has more than three years' experience in teaching. 